BAKTIMAS

Jurnal Pengabdian pada Masyarakat
Vol. 1, No. 4,

Desember 2019
eISSN 2685-113x

pISSN 2685-0303

\title{
Pelatihan Marketing Strategi Tenaga Pemasaran Guna Pencapaian Target Penjualan
}

\author{
Arjang $^{1 *}$, Harwin $^{2}$, Wahyuddin Hamid ${ }^{3}$, Andi Risma Jaya ${ }^{4}$ \\ ${ }^{1,2}$ Prodi Manajemen, Fakultas Ekonomi, Universitas Indonesia Timur \\ ${ }^{3}$ Prodi Administrasi Negara, Pascasarjana, Universitas Indonesia Timur \\ ${ }^{4}$ Prodi Administrasi Negara, Fisip, Universitas Indonesia Timur \\ ${ }^{1}$ ab.arjan@yahoo.com ${ }^{2}$ inyo.mamen@gmail.com \\ ${ }^{3}$ wahyuddinhamid159@gmail.com ${ }^{4}$ jayarisma29@gmail.com
}

DOI : $10.32672 / \mathrm{btm} . v 1 \mathrm{i} 4.1723$

\begin{abstract}
Failure to achieve sales targets has implications for not achieving the company's profit targets. The most basic problem, is preparing a plan and a team that will provide a solution to the problem. Marketing strategy training has a fundamental goal of increasing sales and achieving competitive advantage with a sustainable perspective. Marketing strategies include short-term plans and long-term market-oriented marketing activities in order to contribute to the company's goals and marketing objectives. For this reason, PT. Tata Finapedia, a marketing agency services company, built a partnership with the University of Eastern Indonesia (UIT), to help train marketing staff. The success of a marketing strategy is measured by sales performance and company profit growth. This training is expected to help explain the latest aspects of marketing strategy so as to increase the ability in the formulation and analysis of marketing strategies in the business environment of PT. Tata Finapedia.
\end{abstract}

Keywords: Training, Marketing, Marketing, Sales

\begin{abstract}
ABSTRAK
Kegagalan dalam pencapaian target penjualan, berimplikasi pada tidak tercapainya target profit perusahaan. Problem paling mendasar, adalah menyiapkan perencanaan dan tim yang akan memberikan solusi bagi problem itu.(Jørgensen 2018) Pelatihan marketing strategy memiliki tujuan mendasar yaitu meningkatkan penjualan dan mencapai keunggulan kompetitif dengan perspektif yang berkelanjutan.(Rowe and Clark 1927) Marketing strategi mencakup rencana jangka pendek dan jangka panjang kegiatan pemasaran dengan berorientasi pasar dalam rangka memberikan kontribusi terhadap tujuan perusahaan dan tujuan pemasaran. Untuk itu, PT. Tata Finapedia, perusahaan jasa keagenan marketing, membangun kemitraan dengan Universitas Indonesia Timur (UIT), guna membantu pelatihan bagi jajaran marketing. Keberhasilan strategi pemasaran diukur dari kinerja penjualan dan pertumbuhan laba perusahaan. Pelatihan ini diharapkan membantu memaparkan aspek marketing strategy terkini sehingga mampu meningkatkan kemampuan dalam formulasi dan analisis strategi pemasaran di lingkungan bisnis PT. Tata Finapedia.
\end{abstract}

Kata Kunci: Pelatihan, Marketing, Pemasaran, Penjualan 
BAKTIMAS

Jurnal Pengabdian pada Masyarakat
Vol. 1, No. 4,

Desember 2019
eISSN 2685-113x

pISSN 2685-0303

\section{PENDAHULUAN}

Perusahaan yang mampu terus bertahan dalam persaingan pasar yang ketat adalah perusahaan yang mampu mengantisipasi perkembangan dunia binis dan industri yang semakin dinamis telah menciptakan persaingan yang semakin ketat. Syarat yang harus dipenuhi oleh suatu perusahaan agar dapat terus eksis dalam persaingan yaitu terus berusaha mencapai tujuan untuk menciptakan dan mempertahankan customer. Salah satu langkah yang dapat ditempuh agar tujuan tersebut dapat tercapai adalah melalui strategi pemasaran (marketing strategy) yang tepat.(Neal 2009)

Awalnya perusahaan perlu untuk menetapkan sasaran pemasaran (marketing objectives), baru proses selanjutnya adalah merumuskan dan menyusun Marketing Strategy \& Planning (Strategi dan Perencanaan Pemasaran). Marketing Strategy adalah suatu cara atau metode yang digunakan untuk mencapai sasaran pemasaran tersebut. Marketing plan adalah serangkaian aktifitas yang perlu dijalankan yang merupakan implementasi dari Marketing Strategy dalam rangka pencapaian sasaran pemasaran. Hasil perumusan dalam Marketing Strategy merupakan output bagi penyusunan marketing plan. Dalam marketing plan berbagai program dan aktifitas pemasaran direncanakan, dirancang dan diterapkan.(Grönroos 1994)

Marketing Strategy memiliki tujuan mendasar yaitu meningkatkan penjualan dan mencapai keunggulan dengan kompetitif dengan perspektif yang berkelanjutan. Marketing Strategy mencakup rencana jangka pendek dan jangka panjang kegiatan pemasaran dengan berorientasi pasar dalam rangka memberikan kontribusi terhadap tujuan perusahaan dan tujuan pemasaran. Keberhasilan strategi pemasaran diukur dari kinerja penjualan dan pertumbuhan laba perusahaan. Training Marketing Strategy Competitive ini akan membantu memaparkan aspek marketing strategy terkini sehingga mampu meningkatkan kemampuan dalam formulasi dan analisis strategi pemasaran di lingkungan bisnis yang kompetitif.(Tjiptono 2014)(Saladin and Oesman 2003)

Dalam iklim kompetisi yang begitu mematikan, hanya perusahaan yang mampu mengantisipasi tantangan pasar, yang akan terus mempertahankan kinerjanya, memantapkan posisi tawar, dan menjaga kesinambungan usaha berikut produk dan karyawannya. Untuk itu keterlibatan institusi pendidikan, sebagai basis pemikiran dan pengembangan keilmuan, sangat dibutuhkan, melalui kerjasama kemitraan, baik riset maupun pendidikan dan pelatihan.(Sutisna 2003).

\section{Tujuan Kegiatan}

Secara umum dan khusus, kegiatan ini memiliki tujuan yang sangat berguna, dalam menunjang pencapaian target sebagai marketing, yakni:

1. Marketing mampu menganalisis, merumuskan, dan merancang marketing strategi dan marketing plan yang layak diterapkan.

2. Memahami konsep dan implementasi marketing strategi \& planning

3. Mampu melakukan analisa pasar dan produk

4. Mampu melakukan analisis SWOT

Mampu mengaplikasikan berbagai bahan pelatihan dalam praktik kerja 
Arjang, Harwin, Wahyuddin Hamid, Andi Risma Jaya

\section{METODE PELAKSANAAN}

\section{Presentasi}

Presentasi adalah suatu kegiatan berbicara di hadapan banyak hadirin atau salah satu bentuk komunikasi. Presentasi merupakan kegiatan pengajuan suatu topik, pendapat atau informasi kepada orang lain. Berbeda dengan pidato yang lebih sering dibawakan dalam acara resmi dan acara politik, presentasi lebih sering dibawakan dalam acara bisnis. Tujuan dari presentasi bermacam-macam, misalnya untuk membujuk (biasanya dibawakan oleh wiraniaga), untuk memberi informasi (biasanya oleh seorang pakar), atau untuk meyakinkan (biasanya dibawakan oleh seseorang yang ingin membantah pendapat tertentu). Agar bisa pandai berpresentasi, orang sering kali belajar pada para pakar presentasi. Juga, ada banyak pembicara terkenal yang sering kali diamati oleh orang-orang yang ingin pandai berbicara di hadapan umum.(Tulasi 2012).

\section{Diskusi}

Diskusi adalah sebuah interaksi komunikasi antara dua orang atau lebih/kelompok. Biasanya komunikasi antara mereka/kelompok tersebut berupa salah satu ilmu atau pengetahuan dasar yang akhirnya akan memberikan rasa pemahaman yang baik dan benar. Diskusi bisa berupa apa saja yang awalnya disebut topik. Dari topik inilah diskusi berkembang dan diperbincangkan yang pada akhirnya akan menghasilkan suatu pemahaman dari topik tersebut.

\section{Studi Kasus}

Studi kasus adalah salah satu metode penelitian dalam ilmu sosial. Dalam riset yang menggunakan metode ini, dilakukan pemeriksaan longitudinal yang mendalam terhadap suatu keadaan atau kejadian yang disebut sebagai kasus dengan menggunakan cara-cara yang sistematis dalam melakukan pengamatan, pengumpulan data, analisis informasi, dan pelaporan hasilnya. Sebagai hasilnya, akan diperoleh pemahaman yang mendalam tentang mengapa sesuatu terjadi dan dapat menjadi dasar bagi riset selanjutnya. Studi kasus dapat digunakan untuk menghasilkan dan menguji hipotesis

\section{Simulasi}

Simulasi adalah suatu proses peniruan dari sesuatu yang nyata beserta keadaan sekelilingnya (state of affairs). Aksi melakukan simulasi ini secara umum menggambarkan sifat-sifat karakteristik kunci dari kelakuan sistem fisik atau sistem. Dalam pelatihan ini simulasi berfungsi untuk menguji kedalaman analisis dan pemikiran marketing atau tenaga pemasaran. 
BAKTIMAS

Jurnal Pengabdian pada Masyarakat
Vol. 1, No. 4,

Desember 2019
eISSN 2685-113x

pISSN 2685-0303

\section{Evaluasi}

Evaluasi merupakan saduran dari bahasa Inggris "evaluation" yang diartikan sebagai penaksiran atau penilaian. Dengan kata lain bahwa evaluasi adalah kegiatan yang dilakukan berkenaan dengan proses untuk menentukan nilai dari suatu hal. Pendapat lain menjelaskan bahwa evaluasi adalah proses untuk mempertimbangkan sesuatu barang, hal atau gejala dengan mempertimbangkan beragam faktor yang kemudian disebut Value Judgment.

Keseluruhan materi kegiatan, ditujukan guna membangun kemampuan individu marketing, untuk terus menemukan sukses pribadi dan kualitas kerja yang baik serta terus melakukan perbaikan dalam proses kerja dengan memberdayakan kemampuan, kekuatan berpikir dan pendekatan emosional menjadi hal yang menjadi concern yang utama sebagai upaya menemukan performa terbaiknya sebagai seorang marketing (Martiman 2014)(Putro, Semuel, and Brahmana 2014)

\section{HASIL DAN PEMBAHASAN}

Pengabdian Kepada Masyarakat ini, dilaksanakan secara kontinyu, sebagai bagian dari kemitraan PT. Tata Finapedia, sebuah perusahaan jasa keagenan tenaga pemasaran, yang telah menjalin kerjasama dengan UIT, melalui Fakultas Ekonomi. Sejak tahun 2015. Adapun hasilnya dapat dikemukakan sebagai berikut:

1. PT. Tata Finapedia, menyiapkan peserta yang terdiri dari tenaga marketing, yang direkrut melalui jalur penerimaan pegawai.

2. Jumlah peserta pelatihan setiap kegiatan berjumlah antara 10-15 orang.

3. Pelaksanaan kegiatan pengabdian ini, berlangsung selama dua hari, dilaksanakan mulai pukul 10.00-12.00 WITA.

4. Tempat pelaksanaan Kegiatan di Kantor PT. Tata Finapedia, Jalan Pengayoman Kompleks Mawar, Panakkukang Mas Makassar.

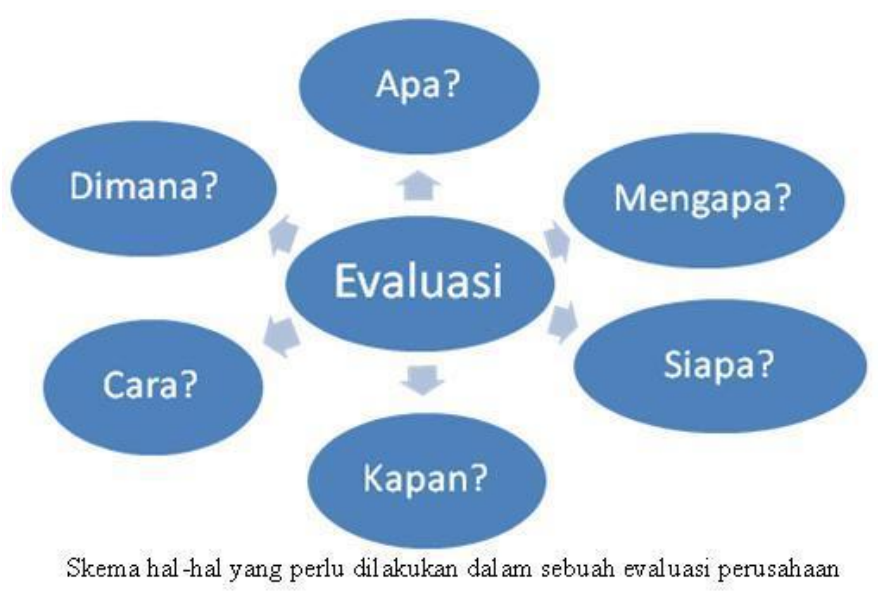

Kegiatan Pelatihan hasilnya dapat kami uraikan sebagai berikut: 
Arjang, Harwin, Wahyuddin Hamid, Andi Risma Jaya

Dosen yang melaksanakan kegiatan berjumlah empat orang, dengan menyertakan mahasiswa berjumlah emat orang. Kegiatan berlangsung sesuai rencana.

1. Pada hari pertama 15 November 2018 kegiatan diikuti 10 orang peserta. Semua peserta mengikuti hingga berakhirnya pemaparan materi pelatihan. Pengukuran keaktifan peserta diketahui melalui pertanyaan yang diajukan oleh peserta, berdasarkan presentase dan studi kasus.

2. Pada hari kedua 15 November 2018 kegiatan dilanjutkan, dengan melakukan uji coba keterampilan kepada setiap peserta secara bergantian, dengan mengasah ketajaman dan kemampuan pada penguasaan produk dan kekuatannya.

3. Peserta diminta menyampaikan pendapat terkait keunggulan dan kelemahan produk pesaing. Keunggulan kompetitif produk yang dipasarkannya.

4. Semua dosen pendamping melakukan pembimbingan pada metode analisis dan evaluasi.

5. Diskusi aktif dirangkaikan dengan koreksi detail pada kemampuan dan kekurangan marketing.

6. Peserta diminta mengisi lembar evaluasi sebagai akhir dari pelatihan, bertujuan mendapatkan gambaran riil yang dipunyainya.

\section{Temuan Diskusi}

Sejumlah temuan dalam pelatihan, bisa dirumuskan secara lengkap dalam poin uraian di bawah ini :

1. Marketing PT. Tata Finapedia, dinilai kurang memiliki kemampuan penguasaan produk yang efektif dimulai dari strategi marketing yang informatif.

2. Sebagai marketing, peserta minim dalam strategi yang baik, guna membantu mendefinisikan visi, misi, dan tujuan bisnis, serta memberikan kerangka kerja yang dibutuhkan untuk mencapai tujuan perusahaan.

3. Marketing kurang memahami strategi marketing, yang memungkinkan dapat mempengaruhi cara mereka dalam merespon menjalankan keseluruhan bisnis, di pasar.

4. Diperlukan perancangan strategi dan dikembangkan secara konsultatif dengan seluruh anggota tim, manajer maupun pimpinan perusahaan.

Secara umum strategi marketing yang comprehensive, belum menjadi pengetahuan dasar bagi peserta.

\section{Simpulan dan saran}

\section{PENUTUP}

PT. Tata Finapedia, harus melakukan pola pelatihan yang mengarah pada kemampuan penguasaan produk, keunggulannya, kelebihan perusahaan, daya dukung regulasi dan iklim bisnis yang memberikan daya dorong bagi marketing dalam berkreasi selama proses penjualan. Tingkat pendidikan marketing, yang ratarata berusia muda, tamatan pendidikan menengah setara SLTA, tidak memiliki pengalaman, menyebabkan daya kreasi dan sifat ulet serta tanggguh belum mereka miliki. Pelatihan ini merekomendasikan; 
1. Diperlukan standarisasi pendidikan minimal sarjana, sehingga memungkinkan daya nalar dan kreatifitas mereka bisa berkembang.

2. Penerimaan tenaga pemasaran setingkat SLTA, hanya mungkin jika diikuti dengan keterangan pengalaman kerja minimal 2 tahun untuk bidang yang sama.

\section{UCAPAN TERIMA KASIH}

Ucapan terima kasih kepada Direktur Utama PT. Tata Finapedia, Ibu Tuty Handayani, Ketua Lembaga Penelitian dan pengabdian Pada Masyarakat (LPPM) UIT, yang telah membantu penyediaan anggaran kegiatan, Rektor dan Wakil Rektor III dan IV UIT, sehingga kegiatan PKM ini dapat terlaksana.

\section{DAFTAR RUJUKAN}

Grönroos, Christian. 1994. "From Marketing Mix to Relationship Marketing: Towards a Paradigm Shift in Marketing." Management Decision.

Jørgensen, Steffen. 2018. "Marketing.” In Handbook of Dynamic Game Theory,.

Martiman. 2014. "Strategi Pemasaran Barang Dan Jasa Perusahaan Melalui Media Iklan." Jurnal Ilmiah Widya.

Neal, Carolyn Pollard. 2009. "Marketing Management." Marketing Management.

Putro, SW, H Semuel, and RK Brahmana. 2014. "PENGARUH KUALITAS LAYANAN DAN KUALITAS PRODUK TERHADAP KEPUASAN PELANGGAN DAN LOYALITAS KONSUMEN RESTORAN HAPPY GARDEN SURABAYA.” Jurnal Manajemen Pemasaran.

Rowe, J. W. F., and F. E. Clark. 1927. "Principles of Marketing." Economica.

Saladin, Djaslim, and Yevis Marty Oesman. 2003. "Intisari Pemasaran Dan Unsur-Unsur Pemasaran." Cetakan Ketiga, Bandung: Linda Karya.

Sutisna. 2003. "Perilaku Konsumen: Teori Dan Penerapannya Dalam Pemasaran." Ghalia Indonesia, Jakarta.

Tjiptono, Fandy. 2014. "Pemasaran Jasa - Prinsip, Penerapan, Dan Penelitiab." In 1,.

Tulasi, Dominikus. 2012. "Komunikasi Pemasaran.” Humaniora. 